\title{
Resistance to the Global Poliomyelitis Eradication Initiative - Perceptions and Perspectives of Recipients: a review of the Northern Nigerian Episode
}

\author{
Victoria N. Omole ${ }^{1}, \mathrm{Nmadu}_{\mathrm{GA}}{ }^{1}$, Oyefabi $\mathrm{A}^{1}$ and Audu $\mathrm{O}^{2}$ \\ ${ }^{1}$ Department of Community Medicine, Kaduna State University (KASU), Kaduna, Nigeria \\ ${ }^{2}$ Department of Epidemiology \& Community Medicine, Benue State University, Makurdi, Nigeria \\ Corresponding Author:Dr. Victoria Nanben Omole, Department of Community Medicine, \\ College of Medicine, Kaduna State University, Nigeria, \\ E-mail - nvable110@yahoo.com
}

\begin{abstract}
In 1980, after decades of efforts by the World Health Organization, the World Health Assembly endorsed the formal declaration of the global eradication of smallpox. Since the successful eradication of smallpox in late 1970s, the last case of wild smallpox occurring in Somalia in 1977, mankind has been hopeful and optimistic that the eradication of other diseases is not only feasible, but possible. Considerations and even attempts have since then been made of eradicating other diseases such as poliomyelitis, mumps, guinea worm disease etc. As of 2008, the Carter Center International Task Force for Disease Eradication declared six additional diseases as potentially eradicable: lymphatic filariasis (elephantiasis), measles, mumps, rubella, poliomyelitis and pork tapeworm.

The initiative to eradicate poliomyelitis formally started as a public-private partnership led by national governments and spearheaded by the World Health Organization (WHO) and other partners and stakeholders in 1988. It has 4 major strategies to achieve this goal, namely: routine immunization, supplementary immunization, surveillance and targeted "mop-up" campaigns.

Nigeria is one of only three countries where poliomyelitis lingered as a public health concern; others being Pakistan and Afghanistan. (However, the wild poliovirus transmission in Nigeria is limited to a few northern states). Incidences of resistance to the administration of the vaccine by communities have been reported; some of which have been extreme in nature, including reports of violent attacks against health workers, sometimes with fatal outcomes.

The question remains that: 'Why would communities that hitherto have not resisted healthcare suddenly revolt against what is apparently endorsed by the global community as a good or positive intervention to a health challenge?' This paper seeks to look into this matter by probing into/reviewing the perceptions and perspectives of resistant communities' and identifying the reasons behind this phenomenon.
\end{abstract}

Keywords: immunization, poliomyelitis, resistance, eradication

\section{INTRODUCTION}

'Health for All' is a popular and familiar health slogan, globally. The triumph of humanity over small pox in the last century has boosted its confidence and determination to fulfill the same feat with other diseases. This led to the birth of the Global Poliomyelitis Eradication Initiative 
(GPEI)by the World Health Organization (WHO), Rotary International, the US Centers for Disease Control \& Prevention (CDC) and the United Nations Children's Fund (UNICEF) in 1988. The initial resolve was to eradicate poliomyelitis by the year 2000. Eradication refers to the permanent reduction to zero of the global incidence and prevalence of an infection [1-3]. As an English word, the term "eradicate" means to "uproot" or to "pull or tear up by the roots". Significant progress has since been attained globally by the initiative. For instance, within it's first 5 years, the number of countries reporting zero poliomyelitis cases increased from 107 to 144; although it still remained endemic in many countries of sub-Saharan Africa and Asia (particularly in the Indian subcontinent) [4]. Nigeria, India, Pakistan and Afghanistan were of international concern as countries with endemic disease [5] and challenges, with regards to eradication such as political instability or resistance to vaccination. In 2003, Nigeria alone accounted for about $45 \%$ of poliomyelitis cases globally and $80 \%$ of cases reported from the African region [6].

By 2012, India marked a full year with no cases of poliomyelitis. In the same year, an article by Desmarais Scott reported that Nigeria remained 'Africa's only remaining polio-endemic country, and the number of confirmed new wild poliovirus cases was increasing, eventually reaching 122 that year' [7]. Unlike countries in the Indian sub-continent where polio-endemicity and eradication failure were largely due to medically explainable factors such ashigh numbers of subclinical cases of polio and the occurrence of vaccine-derived polio; as well as extra-medical factors such as civil strife and political instability ${ }^{8}$, in addition to these factors, the situation in Nigeria was slightly different and peculiar. Majority of reported cases of poliomyelitis occurred in the northern parts of the country, where resistance to polio vaccination started initially as a passive boycott in some northern states in 2003 and gradually deteriorated to violent expressions of non-acceptance, escalating in the death of about 13 vaccinators by insurgents a decade later [78]. This article sets out to review some of the factors attributable to the fore-going scenario.

\section{Socio-demographics and History}

Located on the coast of West Africa, the Federal Republic of Nigeria is made up of 36 states and the Federal Capital Territory. Northern Nigeria currently consists of 19 out of these 36 states. The 19 states are further grouped into 3 geo-political zones, namely: north-central, north-east and north-west. The last national census in Nigeria showed that out of the top 10 states with the highest populations, five (namely, Kano, Kaduna, Katsina, Bauchi and Jigawa) are located in the north-western and north-eastern zones [9]. Many (but certainly not all) of the cases of poliomyelitis in northern Nigeria were reported from states within the north-western and northeastern zones [10].

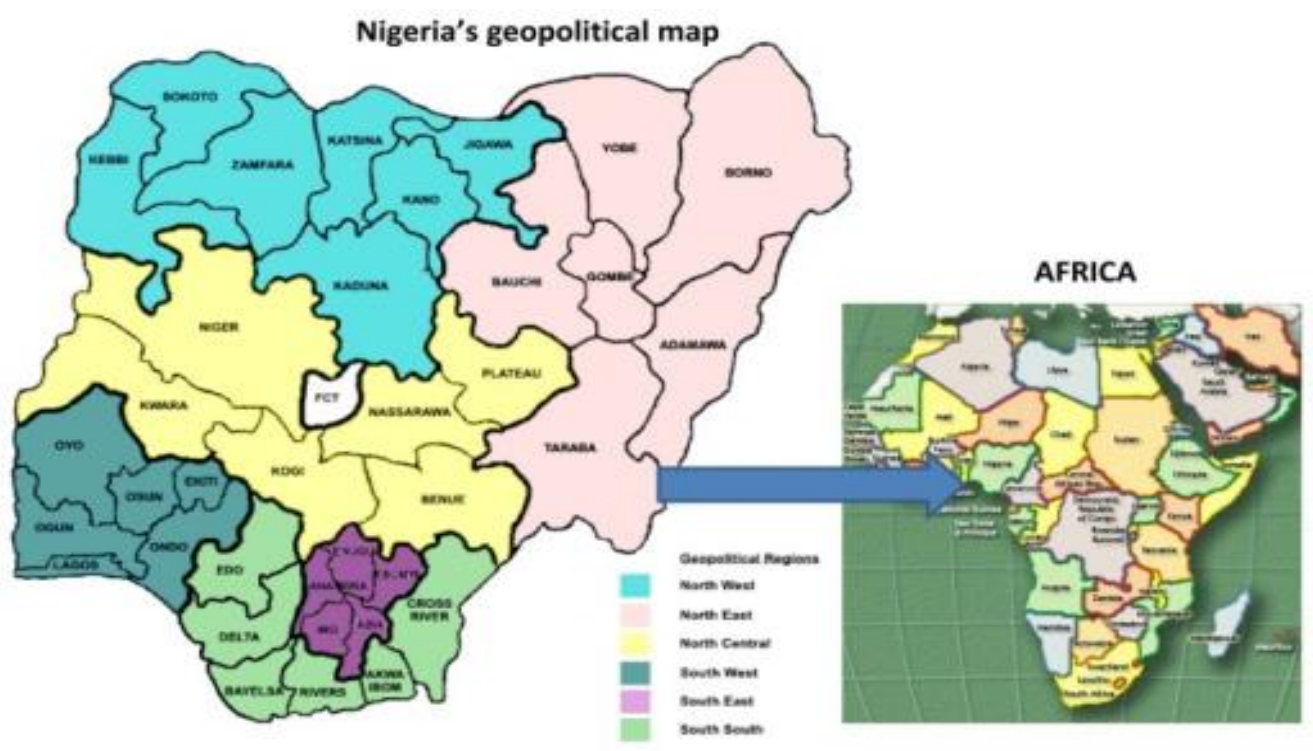


This part of the country is predominantly and historically inhabited by people of Hausa-Fulani extraction, ethnically; majority of whom are of Islamic persuasion. Many other ethnic groups such as the Kanuris, Beri-beri are also found here. Blessed with diverse, beautiful and rich heritages and cultures, they have been ruled by long-existing monarchical systems and dynasties that date back to many centuries. These rulership systems were encountered by the British colonialists and remained untampered by them, by the establishment of an indirect style of governance prior to the independence of the Nigerian state as a nation [11].

\section{Health Indices and Utilization of Health Services}

Compared to other parts of the country, historically, northern Nigeria encountered European (western) civilization much later. The region also shied away from influences perceived to be western, embracing them with caution and suspicion. This stance of conservativeness, among other factors, has contributed to glaring disparities in diverse areas and aspects of sociocultural life as well as socioeconomic development, including healthcare indices between the northern and southern parts of the country. For instance, morbidity and mortality rates among vulnerable groups are higher in the region [12]. Data from the National Demographic and Health Survey (NDHS) of 2013 show that both north-west and north-east zones recorded the highest under-five (and other childhood) mortality rates in the country [13]. Maternal morbidity and mortality burdens are also highest in these zones ${ }^{14}$. Data for the utilization of health services, both stationary (facility-based) and mobile (outside health facilities), are lower relative to those in other parts of the country [14-16].

\section{Perceptions and Perspectives}

Perception has been acclaimed to be equal to, and in some instances, even stronger than reality [17]. Perception is often an outcome of perspective; how people view and interpret issues. A review of the perceptions and perspectives of these people groups may go a long way in understanding, or even empathizing with their non-compliant positions, as recipients of a public health intervention. Furthermore, it could help healthcare providers and policy-makers develop more effective and recipient-friendly methods and strategies for attaining health goals and targets.

\section{Methods and approaches}

Details regarding the polio vaccine and methods of its administration as well as approaches towards the target populations appeared to be shrouded or surrounded by controversial concerns such as -

- The intense and insistent publicity, mobilization and marketing strategies accorded to the polio vaccine relative to other vaccines and health services or interventions [8]. This includes blending both conventional and non-conventional methods such as electronic media advertisements, community workshops, town criers etc. This engendered a negative curiosity regarding the vaccine.

- The house-to-house approach of vaccinators and health workers going door to door [15], unlike other health services that could only be accessed strictly at stationary health facilities; and most times within specified "working hours". This was viewed as intrusive of privacy in some quarters [18] and certainly raised suspicion among recipient communities, where conservatism and the "purdah" system are widely observed.

- The use of incentives, free-of-charge: the intervention was accompanied with both medical incentives (such as the administration of anti-helminthics, vitamin A supplementation etc) and non-medical incentives (such as sweets, sachets of milk, toys etc to children and soap or detergents to their mothers) [10].

- The unique route of administration of the vaccine with its widely acknowledged and acclaimed advantages, as good and as true as they are, may have pardoxically also contributed to the controversies too. The oral means of administration of the polio vaccine, as against the injectables that most other vaccines in the routine immunization schedule are, may have been a potential source of concern to the uninformed. 


\section{Suspicion and distrust}

Trust is a priceless asset that ought to be highly valued and jealously guarded. The lack or absence of it gives room for the breeding of undue suspicion and costly distrust. This is more so pertinent when public trust in the context of healthcare is at stake [19]; for the outcomes and consequences of such could be unquantifiable. Some of the factors remotely or directly associated with this widespread resistance to the polio vaccine include -

- It's close association with the western hemisphere and institutions in the West, which made it difficult for conservationists in northern Nigeria to dissociate the initiative from the foreign policies and actions of western nations in the Middle East and Muslim world at large [18].

- Closely connected to the fore-going point are anti-colonial sentiments (why highlighted) stemming from the British colonial conquest, occupation and dealings with the caliphates that had ruled the north [18]. Such sentiments still linger among pockets of conservationists in the region.

- Also there have been expressions of cynicism regarding the focus on polio "only" or alone, as a priority in the midst of other prevailing childhood diseases associated with grave complications and mortality burdens such as measles and malaria; unattended preventive measures such as sanitation, potable water supply, nutrition etc; as well as other socio-developmental issues in other sectors or areas in the polity such as education, infrastructural development, agriculture etc [18], questioning the apparent neglect of these fundamental issues.

- Finally, the region had also witnessed and suffered some unfortunate mishaps in the area of health interventions such as the drug trial incident involving 'Trovan' (trovafloxacin), a meningitis drug on 200 children in Kano in 1996. This left many northern communities with the unpleasant after-taste of about 11 participating children dying and others suffering paralysis, brain damage and slurred speech; attributable by the communities to the drug trial $[15,18]$. And even more directly associated with the subject matter (polio), reports of vaccine-associated paralytic polio (VAPP), which rarely occurs among recipients of the vaccine or their contacts [20], were further disturbing.

\section{Rumours and misinformation}

Aberrations and breaches in information dissemination engender misinformation and cause rumours to thrive. Furthermore, they erode public confidence in the health system and in the long run, fuel belief in these rumours. This was no exception in the polio resistance saga in northern Nigeria. No doubt, the place of appropriate and adequate information disseminated "up front" and via locally recognized and acceptable channels or authorities was under-estimated in this region. Some of the prevailing rumours regarding the polio vaccine include claims that it was "intentionally" contaminated with anti-fertility hormones (such as oestradiol) and harmful or infectious agents (such as carcinogens and HIV). [10,15]. All these contributed to undermining efforts towards public acceptance of the vaccine and the possibility of polio eradication in the within the expected time target [5].

\section{Ethical Considerations and Public Health Interventions}

As laudable as initiatives to eliminate and eradicate disease entities of public health concern are, they are not devoid of ethical challenges and considerations (just like private or personal physician-patient or client encounters). A fundamental ethical principle that appeared to have been either neglected or under-estimated in the fore-going overview is that of autonomy. This translates into the principle of respect for persons (which includes their perceptions and perspectives, too) or informed consent [21-22]. This principle takes into consideration two important factors, namely- information communication in a manner comprehensible to recipients of health services or interventions and permission or willingness of the recipients. It is quite obvious that the fears and suspicions of these communities were not adequately allayed by a two-way transfer of information; and genuine questions they had regarding the vaccine were 
not adequately answered (at least to their satisfaction). Furthermore, their consent to submit their children and wards to such medical interventions was perceived as being 'taken for granted' [18]. This brings in the matter of medical paternalism, where government and health authorities at both local and national as well as regional and global levels make decisions that border around health and welfare (or even life) on behalf of their populace without due consultation with the end-users and stakeholders concerned [23]. It interferes with the individual(s) liberty of action [24]; and this will eventually undermine their compliance and co-operation with the intervention in question as well as contribute to the failure of the initiative to realize it's set out goals. Granted, in public health (unlike patient-physician encounters or scenarios), sometimes a direct, one-on-one informed consent may not always be feasible, particularly in some developing countries. However, these persons usually live in fairly organized communities with recognized hierarchies of representatives and authorities, who are often more trusted, believed and confided in that 'stereotype' health officials or authorities. Partnering with these influential community personalities and leaders, particularly prior to the introduction and implementation of new or suspicious public health interventions apparently promises to yield better outcomes amongst conservative (and potentially resistant) groups [18].

Finally, the point also arises that where is the line drawn between upholding the views and rights of pockets of 'conservative' healthcare recipients and the ideals of safe-guarding the welfare of the general public and global community? Is there any moral or ethical justification in making interventions such as mass vaccinations mandatory? Certainly, a reasonable and fair balance ought to be maintained between the two extremes of regarding the rights of individuals to declining or turning down health interventions and the common good of the general public [25]. This is even more pertinent when the diseases in question are communicable or infectious in nature; as human hosts or reservoirs still pose a potential source of spread to other susceptible people and places where zero levels had hitherto been attained. Such was the situation in 2003, following the boycott of the polio vaccine in northern Nigeria [15]. In Nigeria, the number of polio cases increased by about $30 \%$ the following year and cases of wild polio virus traceable to Nigeria were recorded in both neighboring and distant countries [26], thus turning the hands of the clock backwards. Therefore, when the common good, safety and welfare of others is at stake, careful dialogue, negotiations and advocacy are recommended to woo and win the resisting party or parties. Secondly, mandatory vaccinations have always raised controversies and arguments as to their moral or ethical justification [25]. As a result of this, it is usually better to allow every situation to justify itself. For instance, cases abound of declinations and/or exemptions based on factors such as personal convictions, religious beliefs, medical conditions, vaccine safety etc. The view of whether these factors are valid, legitimate or justifiable is often subjective, and therefore subject to endless debates. However, advocacy should embrace the principles of autonomy, along with informed consent and the respect of individual(s), while leaning more on voluntary, rather than mandatory mass vaccinations [27].

\section{Conclusions}

The goal of attaining disease control, elimination or eradication globally is a desirable public health ideal which lies not only in the hands of national governments and international health authorities. Public health is public interest; and all members of every community matter in achieving targets of health interventions. The perceptions and perspectives of recipients of these interventions are evident determinants of their outcome as well as whether they are achieved within target time. It is therefore essential to partner with all stakeholders and "end-users" of health programmes alike (such as community and religious leaders), from the stage of conceptualizing health interventions and implementing them. Embracing the social dynamics and ethical contexts counts a lot, as it 'breaks the ice' and contributes to engendering better public acceptance, greater vaccine uptakes and positive outcomes. 


\section{REFERENCES}

1. Dowdle WR. The principles of disease elimination and eradication. Bull World Health Org 1998;76(Suppl 2):22-5.

2. Cochi SL and Dowdle WR. Disease eradication in the 21st century: implications for global health. Strungmann forum report. Vol. 7. Cambridge, MA: MIT Press, 2011.

3. Recommendations of the International Task Force for Disease Eradication. MMWR Recomm Rep 1993;42:1-38

4. CDC. Progress toward global eradication of poliomyelitis, 1988-1993. MMWR 1994;43(27):499503

5. Hopkins DR. Disease Eradication. N Engl J Med 2013;368:54-63.

6. Renne E. Perspectives on polio and immunization in northern Nigeria. Soc Sci Med 2006;63(7):1857-69.

7. Desmarais S. Eradicating polio in Nigeria. McKinsey \& Company, Healthcare Systems \& Services; 2000.

8. Jitratkosol M. The challenges that the global polio eradication initiative faces. Sci Creat Quart 2008 (Univ of Brit Columbia-UBC website). http://www.bioteach.ubc.ca/the-challenges-that-theglobal-polio-eradication-initiative-faces/

9. National Population Commission, Nigeria. Population distribution by sex, state, LGA and senatorial district: 2006 census priority tables Vol. 3(http://www.population.gov.ng/index.php/censuses)

10. Baba MM, Ayivor M. Polio Vaccination in Nigeria: The 'good', the 'bad' and the 'ugly'. J Antivir Antiretrovir 2012;S15-004.

11. Ikime O. The establishment of indirect rule in northern Nigeria. Tarikh 1970;3(3):1-15.

12. Abubakar L. Nigeria: 'Why poor health indices persist'. Daily Trust Newspaper 11 Jan 2016; (interview by Dickson S. Adama).

13. National Population Commission (NPC) [Nigeria] and ICF International. 2014. Nigeria Demographic andHealth Survey (NDHS) 2013. Abuja, Nigeria and Rockville, Maryland, USA: NPC \& ICF International.

14. Ejembi CL, Alti-Muazu M, Chirdan O, Ezeh HO, Sheidu S, Dahiru T. Utilization of maternal health services by rural Hausa women in Zaria environs, northern Nigeria: has primary health care made a difference? J Comm Med PHC 2004;16(2):47-54.

15. Jegede AS. What led to the Nigerian boycott of the polio vaccination campaign? PloS Med 2007;4(3):e73.

16. Adewemimo AW, Msuya SE, Olaniyan CT, Adegoke AA. Utilisationof skilled birth attendance in northern Nigeria: a cross-sectional survey. Midwifery J 2014;30(1):e7-13.

17. Jackson DV. Perception is reality: your strengths matter. J Lead Educ 2011;10(1):115-22.

18. Integrated Regional Information Networks (IRIN). Roots of polio vaccine suspicion. April, 2013. (http://www.irinnews.org/analysis/2013/04/04/roots-polio-vaccine-suspicion).

19. Calnan M, Sanford E. Public trust in health care: the system or the doctor? Qual Saf Health Care 2004;13:92-7.

20. Umar MS. Islam and colonialism: intellectual responses of Muslims of northern Nigeria to British colonial rule. Intl J Bus Soc Sci 2010;1(2):239-43.

21. Chumakov K, Ehrenfeld E, Wimmer E, Agol VI. Vaccination against polio should not be stopped. Nat Rev Microbiol 2007;5:952-8.

22. Beauchamp TL, Childress JF. Principles of Biomedical Ethics, $7^{\text {th }}$ Edition. Oxford. 2013

23. Garrett TM, Baillie HW, Garrett RM. Health care ethics: Principles and problems (4th ed, 2001). Upper Saddle River, NJ: Prentice Hall.

24. Nys TRV. Paternalism in public health care. Pub Health Ethics 2008;1(1):64-72.

25. McKinstry B. Paternalism and the doctor-patient relationship in general practice.Br J Gen Pract 1992;42(361):340-2.

26. Galanakis E, JansenA, Lopalco PL, Giesecke J. Ethics of mandatory vaccination for healthcare workers. Euro Surveill 2013;18(45):20627. 
27. Guerrera M. Finish Polio: Evolutionary medicine principles and the eradication of polio in evolutionary medicine (2007). Central Connecticut State University, Topics in Biology (Bio 490 / 540).

Acknowledgements - Nil

Source of Funding - Nil

Conflict of Interest - Nil 